\title{
11 \\ INDICATORS, BENCHMARKING AND URBAN INFORMATICS
}

\section{ROB KITCHIN, TRACEY P. LAURIAULT AND GAVIN MCARDLE}

\section{INTRODUCTION}

As introduced in Chapter 7, urban dashboards have begun to proliferate in recent years as a form of spatial media for communicating information about cities. These dashboards use a variety of graphing and mapping visualisations to display both static and real-time data concerning all aspects of urban living, including economy, service provision, health, environment, sustainability, quality of life, transport and infrastructure, derived from a number of sources. As such, dashboards constitute a form of urban informatics - that is, they visualise and model spatially referenced data to produce information about how the city is performing, how they work and how their various systems might be improved (Foth, 2009; Burrows and Beer, 2013). Related forms of urban informatics include geographic information systems (GIS) (Chapter 2), digital mapping (Chapter 3), geodesign (Chapter 8), as well city operating systems, and digital kiosks on city streets that provide hyperlinked, touchscreen browsers for discovering travel guide information about a city, such as points of interest, how to get there, local history and so on. As well as providing information for citizens and visitors, the utility of urban informatics is its facilitation of new forms of operational and policy governance for cities.

This chapter considers the technical and political aspects of the spatially referenced data that underpin the urban informatics enacted by city dashboards. It starts by detailing the characteristics of urban indicator data and the process of city benchmarking. City dashboards often include other kinds of data, such as real-time data from various sensors and scanners mostly relating to transport (e.g. bike usage, bus location, road travel speeds) and environment (e.g. weather, pollution, water levels), as well as social media (e.g. maps of Twitter and Instagram activity) and 
crowdsourced data (e.g. the location of potholes or graffiti), however, to keep the discussion focused we concentrate on indicator data. Next we provide a critical examination of indicator data and city benchmarking, setting out concerns relating to data selection and formulation, data quality and data analysis. This is followed by an exploration of urban informatics as data assemblages; that is, as dense amalgams of actors, actants and socio-spatial processes that work together in complex and negotiated ways to produce an urban information system (Kitchin, 2014). In the final section, we detail issues that require future attention, suggesting the need for greater reflection on the data underpinning urban informatics and the detailed mapping out of data assemblages. The argument we put forward can equally be applied to other kinds of urban data or urban informatics such as those produced by GIS, street kiosks and urban control rooms.

\section{URBAN INDICATORS AND CITY BENCHMARKING}

Indicators are recurrent quantified measures that can be tracked over time to provide information about stasis and change with respect to a particular phenomenon (Godin, 2003). Since the early 20th century a variety of social, economic and environmental indicators have been developed to track how nations and cities are performing. Since the early 1990s urban indicator projects have proliferated as a result of the sustainability agenda arising from the 1992 United Nations Conference on Environment and Development (UNCED) in Rio de Janeiro that mandated cities to track indicators related to sustainable development, and the rise of urban managerialism and the desire to reform the public sector management of city services by tracking performance and to implement evidence-based decision-making. Consequently, many cities around the world now routinely generate suites of indicators, using them to track and trace performance, guide policy formulation, and to inform how cities are governed and regulated.

Typically, there are two main types of indicators used to monitor cities. Single indicators consist of a measurement or a statistic related to a particular phenomenon, such as the unemployment rate. The most desirable single indicators are well defined and unambiguous, and have strong representativeness (they measure what they declare themselves to measure). In some cases, indicators are indirect in nature as the phenomenon of interest is intangible or not directly observable, such as the number of patent applications being used as proxy for innovation (Gruppa and Mogee, 2004). Composite indicators combine several single measures using a system of weights or statistics to create a new derived measure, such as a deprivation index that combines several indicators such as household income, employment status, welfare and health status, and access to services into a single overall score (Maclaren, 1996). Composite indicators recognise that different phenomena are interrelated and multidimensional, and that no one indicator can reveal the extent or complexities underpinning an issue such as deprivation.

These kinds of indicator data are rarely produced by spatial media. Rather, urban indicator data are usually derived from administrative datasets and are consumed 
by spatial media. That is, indicator data form key base data for city dashboards, through which they are visualised in various ways to produce information and insight. In general, indicators are deployed in three ways. First, as descriptive or contextual indicators that provide insights into the present state of play and the prevailing trends with respect to a particular phenomenon. Second, as diagnostic, performance and target indicators that provide a means to diagnose a particular issue (such as whether an issue is becoming a problem or is abating), or to assess performance such as effectiveness (whether goals are being met) and efficiency (whether getting the most output for the input) of a policy or programme or organisation (Holden, 2006). Targets can be absolute (to reach a defined level) or relative (to match the performance of another organisation/place). Third, as predictive and conditional indicators that are thought to be useful for predicting and simulating future situations and performances and thus identifying what policy and operational changes might be required in the present to reshape the future in desired ways (Maclaren, 1996).

A common way to determine the performance of a city is to benchmark indicator data both within and across cities, comparing trends between different locales or against best practice. This is often accompanied by scorecarding in which tables of rankings and ratings, along with changes in relative position, are produced to reveal which places are doing well and which are underperforming (Gruppa and Mogee, 2004). Huggins (2009) details three types of area-based benchmarking. First, performance benchmarking that compares how well a place is doing with respect to a set of prescribed indicators. Second, process benchmarking that compares the practices, structures and systems of places. Third, policy benchmarking that compares public policies that influence performance and processes with respect to outcomes and meeting prescribed expectations. Luque-Martinez and Munoz-Leiva (2005) detail that these can be benchmarked in three ways: competitive benchmarking, wherein cities are ranked and rated regardless of whether they want to participate in the process (e.g. the best or most innovative place to live); cooperative benchmarking, where cities cooperate with the benchmarker, providing necessary information but often on the basis that target cities are not direct competitors (e.g.Vital Signs ${ }^{1}$ ); and collaborative benchmarking, where several cities work together to produce standardised indicators and to share knowledge and resources (e.g. FCM Quality of Life Indicators ${ }^{2}$ ). Jones Lang LaSalle report that there are now over 150 city benchmarking initiatives that seek to compare and contrast hundreds of cities globally (Moonen and Clark, 2013). Some of these initiatives benchmark cities across a range of indicators, some focus on particular sectors such as economic performance.

\section{A CRITICAL ASSESSMENT OF URBAN INDICATORS AND CITY BENCHMARKING}

The power of urban indicators is that they seemingly provide quantitative measures that are objective, neutral and independent of external influence, are traceable over 
time and space, are verifiable and replicable, sensitive to change, and are quick and costeffective to collect, process and update (Franceschini et al., 2007). Indicators unambiguously capture and communicate what is occurring with respect to a phenomenon and can be compared across locales. A fact is after all a fact and can be accurately measured (e.g. there are $x$ number of people living in a city; $x$ percentage of them are unemployed) and that fact can be calculated for all cities. But is this really the case?

Many would argue that it is not. Instead they would contend that data do not pre-exist their generation and are the product of the ideas, instruments, practices, contexts, knowledges and systems used to generate, process and analyse them (Ribes and Jackson, 2013); that there is nothing natural or inherent about data and facts. Rather they are epistemological units, made to have a representational form that enables epistemological work. Moreover, how data are ontologically defined and delimited is not simply a neutral, technical process, but also a normative, political, and ethical one that is often contested (Bowker and Star, 1999). Indeed, data about the same phenomena can be measured, recorded, analysed and interpreted in numerous ways (Poovey, 1998), and how we conceive of data, how we measure them and what we do with them actively frame the nature of data (Kitchin, 2014). Urban indicator and benchmarking initiatives inherently express a normative notion about what should be measured, for what reasons and what they should tell us, and are full of values and judgements shaped by a range of views and contexts. Or as Bowker (2005) puts it, data are never raw, but always already cooked.

Moreover, indicator and benchmarking initiatives adopt an instrumental rationality that promote a particular way of understanding the world that on the one hand marginalises other forms of knowing such as 'phronesis (knowledge derived from practice and deliberation) and metis (knowledge based on experience)' (Parsons, 2004: 49), and on the other hand have a number of shortcomings. Cities are highly complex open, contingent systems consisting of a rich, multidimensional set of relations. In seeking to reduce this complexity into a set of simplified, one-dimensional measures, indicators inevitably leave out more than they capture. Moreover, they decontextualise cities from their history, political economy, the wider set of social, economic and environmental relations that frame their development, and their wider interconnections and interdependencies. In other words, a city is much, much more than the sum of its indicators.

With respect to city benchmarking, the method of scorecarding assumes it is both possible and desirable to measure and compare indicator data between cities. Benchmarking assumes there is a normative standard by which cities should be judged, some ideal state they are all seeking to achieve, rather than acknowledging that phenomena in different places differ from one another often for good reasons - cities have different histories and trajectories, varying political economies and varieties of capitalism, different forms of governance and policy ambitions, and varying access to resources and capacities. Why then judge them against one another in a zero-sum ranking when what we might expect or desire them to achieve is different? In other words, is city benchmarking the best way to assess the relative performance of a city? Or does it simply foster imitation designed to game city rankings rather than produce tailored urban policies conditioned to local situations and ambitions?

Further, urban indicator data and associated informatics suffer from a number of technical and methodological issues that are often overlooked or ignored. As with all 
data, because indicators are abstracted, generalised and approximated through their production there are always questions concerning data veracity and quality and how accurately (precision) and faithfully (fidelity) the data represent what they are meant to (especially when using samples and proxies), and how clean (error and gap free), untainted (bias free), consistent (few discrepancies) and reliable (the measurement instrument consistently produces the same quality of results) the data are (Kitchin, 2014). The level of truthfulness and trustworthiness of data also varies over time and place due to different measurement regimes and their changing nature (as technologies, practices and personnel alter) (Ribes and Jackson, 2013).

There are a number of other issues caused by spatial resolution, aggregation and creating composite scores that can produce a range of ecological fallacies. For example, changing the pattern and scaling of the zones used to delimit data (e.g. geographic boundaries), or how they are categorised, changes the pattern of aggregated observations, often in quite dramatic ways. This can change how a city is ranked with respect to other cities. For example, whether data refer to Dublin City Council, Dublin County or the Greater Dublin Area can markedly change the city's unemployment rate and how that rate compares with elsewhere. Similar issues exist with respect to composite indicators, whereby changing the relative weightings of indicators in the formula, or including or excluding some variables, can have a profound effect on the resulting score. Further, composite indicators need to be normalised onto common geographic, time or threshold scales, the weightings set to reflect importance and to prioritsze key interrelationships, and multi-colinearity between variables or conflicts in their commensurability need to be accounted for, but often none of these tasks is performed (Böhringer and Jochem, 2007). As such, these derived data lack a sound scientific base from which to draw definitive conclusions. In other words, even at a purely technical level, indicator data need to be treated with caution rather than them being assumed to reveal the city as it really is.

This is not to say that urban indicator and benchmarking data, or that the spatial media that employ them, are not useful or valuable - they quite patently are - but rather that they need to be treated with suitable caution when used, recognising and compensating for any shortcomings. The same is the case for other kinds of data used or generated by spatial media. One way to achieve this is to map out and be aware of the data assemblage that constitutes an urban informatics initiative.

\section{UNDERSTANDING URBAN INFORMATICS AS DATA ASSEMBLAGES}

In previous work we defined a data assemblage as a socio-technical system composed of many apparatuses and elements that are thoroughly entwined (Kitchin, 2014). The data assemblages that create urban indicator data include: a number of different stakeholder institutions such as city authorities, government agencies, university institutes and software vendors (each of which has differing roles and power to influence/control the system); a range of different actors including statisticians, researchers, developers, technicians and managers; an amalgam of different actants such as computers, servers, screens and databases; a suite of different legal and governmental requirements such 
as data protection laws, licensing regulations, policy initiatives, data standards and software protocols; access to finance such as state funding, research grants and venture capital; an understanding and entwining of different knowledges, theories and models; as well as factors relating to political economy, places, marketplaces and so on. Together these different apparatus and elements work together, sometimes harmoniously other times in friction, to frame, shape and produce urban indicators.

The data such an assemblage produces are thus contingent, relational and contextual, the result of collaboration, negotiation and contestation, and dependent on many actors and factors. This is why the data they produce are never raw, nor are they neutral, essential and objective. Rather, the data are cooked with respect to a negotiated recipe by a team of chefs embedded within institutions that have certain aspirations and goals and operate within wider constraints (Bowker, 2005). It is also why there are so many different types of urban indicators, generated and measured in a variety of ways; hundreds of different city indicator projects that use varying amalgams of indicators and have dashboard interfaces that differ in how the data are presented and interacted with; and there are over 150 different city benchmarking initiatives that employ different types of scorecards using varying suites of indicators, which are given different relative weightings in importance.

It is this variation in city indicator projects that is driving standardisation initiatives that seek to create harmony across projects to enable legitimate comparison. One such initiative that has recently come to fruition is the new International Organization for Standardization (ISO) standard for city benchmarking indicators (ISO 37120: 2014). This was designed and proposed by the Global City Indicators Facility (GCIF) (cityindicators.org), a joint project of The World Bank, UN-Habitat, the World Economic Forum, the Organisation for Economic Co-operation and Development (OECD) and the Government of Canada. The ISO standard is designed to produce standardised global urban data which are verifiable and transparent, certified by an independent third party (World Council on City Data) and thus deemed trustworthy. Cities are required to produce and report up to 100 indicators with respect to 17 themes concerning city characteristics, services, infrastructure and quality of life. Here, several large supra-national agencies joined forces, working with 254 cities across 81 countries, to develop a new global standard for urban data. Such a process is inevitably highly political and involves the playing out of a complicated set of power geometries between institutions and actors, with the design of the standard and the selection of the themes and indicators involving negotiation and diplomacy. In other words, while the standard aims to create rigour and transparency, there was little objective or neutral about its composition, nor the data that it generates and compares.

\section{ISSUES FOR FURTHER REFLECTION}

Spatial media both consume and produce data. In this chapter we have examined the nature of some of the data that spatial media such as city dashboards utilise and visualise, namely urban indicator and scorecard data. The argument we have put forward has been that, however rigorously and systematically such data are generated, they are never essential, raw, objective and neutral. They are always cooked to some recipe. Data are 
the products of socio-technical assemblages composed of many apparatus and elements that work together in complex, negotiated and often unanticipated ways. The production and use of data are always contingent, relational and contextual. Moreover, there are always technical and methodological issues to consider with regards to how data are processed, analysed and interpreted. What that means is that the users of urban indicator and scorecard data need to be mindful of the potential shortcomings of data and their analysis and to remember that the data do not simply show a city as it really is and how it is performing over time or vis-à-vis other cities. The message being communicated through spatial media varies as a function of the data as much as the medium.

The data within spatial media present a particular version of the city as defined by those data. Of course, the data might reveal a very compelling picture of the present state of play that seems to match knowledge derived from other observations and experience. After all we are not suggesting that urban indicator data have no utility or validity, or provide little insight, but rather one needs to assess their veracity and fidelity to make sure that one can be confident in what the data show and how they should be interpreted. This can be quite difficult to do when most city dashboards do not provide the metadata that would enable such an assessment. Rather, the data are displayed using graphs and maps but rarely are they accompanied by information about data lineage or provenance, or data quality, calculated error rates or calibration. The user is simply expected to trust that the data are valid and reliable. The process of standardisation is one way to try and counter such concerns by ensuring that every city generates, processes and analyses its data in the same ways.

Regardless, we feel that much greater reflection and assessment of urban data needs to take place to document the issues associated with different datasets. And this is the case for all kinds of data used and produced by spatial media, not just indicator and scorecard data. Moreover, it is certainly the case that we have little detailed understanding of the composition and workings of data assemblages related to urban indicator and city benchmarking initiatives, city dashboards and urban informatics more broadly. As such, there is a need for a set of empirical case studies that map out in detail the various apparatus, elements and processes that comprise an urban data assemblage. Such studies would give us a much better appreciation for the ways in which urban data are cooked and then consumed.

\section{NOTES}

1. http://www.vitalsignscanada.ca/en/home

2. Federation of Canadian Municipalities (FCM) http://www.municipaldata-donnees municipales.ca/Site/Collection/en/index.php

\section{ACKNOWLEDGEMENTS}

This chapter draws on and reworks material from Kitchin, R., Lauriault, T. and McArdle, G. (2015) 'Knowing and governing cities through urban indicators, city benchmarking and real-time dashboards', Regional Studies, Regional Science, 2: 1-28. The research was funded by an ERC Advanced Investigator award (ERC-2012AdG 323636-SOFTCITY). 


\section{REFERENCES}

Böhringer, C. and Jochem, P.E.P. (2007) 'Measuring the immeasurable - a survey of sustainability indices', Ecological Economics, 63: 1-8.

Bowker, G. (2005) Memory Practices in the Sciences. Cambridge, MA: MIT Press.

Bowker, G. and Star, L. (1999) Sorting Things Out: Classification and Its Consequences. Cambridge, MA: MIT Press.

Burrows, R. and Beer, D. (2013) 'Rethinking space: urban informatics and the sociological imagination', In N. Prior and K. Orton-Johnson (eds), Digital Sociology: Critical Perspectives. Basingstoke: Palgrave. pp. 61-78.

Foth, M. (2009) Preface, in M. Foth (ed.), Handbook of Research on Urban Informatics: the Practice and Promise of the Real-Time City. New York: IGI Global.

Franceschini, F., Galetto, M., and Maisano, D. (2007) Management by Measurement: Designing Key Indicators and Performance Measurement Systems. Berlin: Springer.

Godin, B (2003) 'The emergence of S\&T indicators: why did governments supplement statistics with indicators?', Research Policy, 32: 679-91.

Gruppa, H. and Mogee, M.E. (2004) 'Indicators for national science and technology policy: how robust are composite indicators?' Research Policy, 33 (9): 1373-84.

Holden, M. (2006) 'Urban indicators and the integrative ideals of cities', Cities, 23(3): 170-183.

Huggins, R. (2009) 'Regional competitive intelligence: benchmarking and policymaking', Regional Studies, 44 (5): 639-58.

Kitchin, R. (2014) The Data Revolution: Big Data, Open Data, Data Infrastructures and Their Consequences. London: Sage.

Luque-Martınez, T. and Munoz-Leiva, F. (2005) 'City benchmarking: a methodological proposal referring specifically to Granada', Cities, 22 (6): 411-23.

Maclaren, V.W. (1996) 'Urban sustainability reporting', Journal of the American Planning Association, 62 (2): 184-203.

Moonen, T. and Clark, G. (2013) 'The business of cities 2013: what do 150 city indexes and benchmarking studies tell us about the urban world in 2013?' Jones Lang LaSalle. Available at: http://www.jll.com/Research/jll-city-indices-november2013.pdf (accessed 25 July 2016).

Parsons, W. (2004) 'Not just steering but weaving: relevant knowledge and the craft of building policy capacity and coherence', Australian Journal of Public Administration, 63 (1): 43-57.

Poovey, M. (1998) A History of the Modern Fact: Problems of Knowledge in the Sciences of Wealth and Society. Chicago, IL: University Chicago Press.

Ribes, D. and Jackson, S.J. (2013) 'Data bite man: the work of sustaining long-term study', in L. Gitelman (ed.), 'Raw Data' is an Oxymoron. Cambridge, MA: MIT Press. pp. 147-66. 